\title{
Bodybuilders' body composition: effect of nandrolone decanoate
}

Citation for published version (APA):

van Marken Lichtenbelt, W. D., Hartgens, F., Vollaard, N. B., Ebbing, S., \& Kuipers, H. (2004).

Bodybuilders' body composition: effect of nandrolone decanoate. Medicine and Science in Sports and Exercise, 36(3), 484-489. https://doi.org/10.1249/01.MSS.0000117157.06455.B0

Document status and date:

Published: 01/01/2004

DOI:

10.1249/01.MSS.0000117157.06455.B0

Document Version:

Publisher's PDF, also known as Version of record

Document license:

Taverne

Please check the document version of this publication:

- A submitted manuscript is the version of the article upon submission and before peer-review. There can be important differences between the submitted version and the official published version of record.

People interested in the research are advised to contact the author for the final version of the publication, or visit the DOI to the publisher's website.

- The final author version and the galley proof are versions of the publication after peer review.

- The final published version features the final layout of the paper including the volume, issue and page numbers.

Link to publication

\footnotetext{
General rights Owners
rights.

- You may freely distribute the URL identifying the publication in the public portal. please follow below link for the End User Agreement:

www.umlib.nl/taverne-license

Take down policy

If you believe that this document breaches copyright please contact us at:

repository@maastrichtuniversity.nl

providing details and we will investigate your claim.
}

Copyright and moral rights for the publications made accessible in the public portal are retained by the authors and/or other copyright owners and it is a condition of accessing publications that users recognise and abide by the legal requirements associated with these

- Users may download and print one copy of any publication from the public portal for the purpose of private study or research.

- You may not further distribute the material or use it for any profit-making activity or commercial gain

If the publication is distributed under the terms of Article $25 \mathrm{fa}$ of the Dutch Copyright Act, indicated by the "Taverne" license above, 


\title{
Bodybuilders' Body Composition: Effect of Nandrolone Decanoate
}

\author{
WOUTER D. VAN MARKEN LICHTENBELT ${ }^{1}$, FRED HARTGENS ${ }^{2,4}$, NIELS B. J. VOLLAARD ${ }^{5}$, \\ SPIKE EBBING ${ }^{3}$, and HARM KUIPERS ${ }^{2}$
}

${ }^{1}$ Department of Human Biology, ${ }^{2}$ Department of Movement Sciences, and ${ }^{3}$ Department of Internal Medicine, Maastricht University, THE NETHERLANDS; ${ }^{4}$ Netherlands Centre for Doping Affairs, Capelle aan den IJssel, THE NETHERLANDS; and

${ }^{5}$ Department of Biological Sciences, Centre for Sport and Exercise Sciences, Colchester, UNITED KINGDOM

\begin{abstract}
VAN MARKEN LICHTENBELT, W. D., F. HARTGENS, N. B. J. VOLLAARD, S. EBBING, and H. KUIPERS. Bodybuilders' Body Composition: Effect of Nandrolone Decanoate. Med. Sci. Sports Exerc., Vol. 36, No. 3, pp. 484-489, 2004. Introduction: The use of androgenic-anabolic steroids (AAS) among bodybuilders to increase muscle mass is widespread. Nandrolone decanoate (ND) is one of the most popular misused AAS, although the effects on body composition are equivocal. Therefore, the purpose of this study was to determine the effect of ND on body composition in male bodybuilders, with special reference to muscle mass alterations. Methods: Using a randomized "double-blind" "placebo-controlled" design, 16 experienced male bodybuilders (age: 19-44 yr) either received $\mathrm{ND}\left(200 \mathrm{mg} \cdot \mathrm{wk}^{-1}\right.$, intramuscularly) or placebo for $8 \mathrm{wk}$. Body composition was assessed using the four-component model, combining results from underwater weighing, dual-energy x-ray absorptiometry (DXA), and deuterium dilution. Total bone mineral content and density were measured using DXA. Water compartments (extracellular water [ECW] and intracellular water [ICW]) were determined using deuterium dilution and bromide dilution. Results: ND administration resulted in significant increments of body mass $(+2.2 \mathrm{~kg})$, fat-free mass (FFM: $+2.6 \mathrm{~kg}$ ), and total body water $(+1.4 \mathrm{~kg}$ ). No significant changes in fat mass, percentage fat, ECW, ICW, ECW/ICW ratio, hydration of the FFM, and on bone mineral measurements were observed. Conclusions: The results show that the administration of $200 \mathrm{mg} \cdot \mathrm{wk}^{-1}$ of ND (intramuscularly) for $8 \mathrm{wk}$ significantly increased body mass and FFM, whereas fat mass, bone mineral content, bone mineral density, and the hydration of the FFM remained unaffected. These data indicate that the changes can be attributed to an increase of muscle mass. Key Words: FOUR-COMPONENT MODEL, DEXA, DEUTERIUM DILUTION, UNDERWATER WEIGHING, EXTRACELLULAR WATER, INTRACELLULAR WATER
\end{abstract}

$\mathrm{B}$ odybuilders use exercise, diet, and often androgenicanabolic steroids (AAS) to reduce fat mass (FM) and increase muscle mass. However, the results from studies investigating the effect of AAS on body composition are conflicting. Most studies show an increase in body mass $(5,14,17)$. In several studies, an increase in fat-free mass (FFM) was evident (15-17), whereas in others no change in FFM was observed (5) as a result of AAS administration. Apart from the effect of physical training, condition at the start of AAS use, the dosage, the type of drug, and the duration of AAS administration, differences in the outcome of the body composition studies could to a large extent be

\footnotetext{
Address for correspondence: W. D. van Marken Lichtenbelt, Department of Human Biology, Maastricht University, P. O. Box 616, 6200 MD Maastricht, The Netherlands; E-mail: MarkenLichtenbelt@HB.unimaas.nl. Submitted for publication March 2003.

Accepted for publication October 2003.
}

0195-9131/04/3603-0484

MEDICINE \& SCIENCE IN SPORTS \& EXERCISE E $_{\circledast}$

Copyright (C) 2004 by the American College of Sports Medicine

DOI: 10.1249/01.MSS.0000117157.06455.B0 attributed to the methods used. For instance, in studies where no change in FFM was observed underwater weighing was the method of choice $(5,7,8)$, whereas in those that found significant increases the skinfold method was practiced $(1,19)$.

It is not yet clear how much of the AAS-induced increment of the FFM is indeed muscle mass. AAS have been shown to increase muscle mass $(3,19)$. However, Hervey et al. (17) suggest that at least part of the increase of FFM was caused by fluid retention. This is supported by the study of Holma (18) that demonstrated that AAS use can result in an increase of the blood volume by over $15 \%$. Therefore, it would be useful to obtain more information on changes of the interstitial and intracellular fluid compartments by the administration of AAS.

To determine the FM and FFM, often skinfolds, bioimpedance analyses, or the traditional gold standard (underwater weighing) are used. All those methods, however, assume a fixed hydration of the FFM and also a fixed bone mineral concentration in FFM, both affecting the results from densitometry. One of the best methods for determining the body composition available at the moment is the socalled four-compartment (4C) model (10). This model in- 
cludes measurements of total body water, total bone mineral content, as well as body density (20). Thus, fewer assumptions are made than with hydrostatic weighing alone, resulting in a higher accuracy in subjects that deviate from the mean assumed values. Moreover, it is possible to calculate the hydration of the FFM (12). So far, the 4C model has not been used in published studies to investigate the body composition of bodybuilders or the effect of AAS.

One of the most frequently used AAS by strength athletes is nandrolone decanoate (ND). Strength athletes are convinced that ND increases body mass and lean mass more than does strength training alone, although scientific data do not support these claims unequivocally $(5,7,8,15,19)$. Therefore, the aim of this study was to investigate the effect of ND on body composition, and hydration of the FFM in bodybuilders, to estimate the impact on muscle mass.

\section{METHODS}

\section{Approach to the Problem and Experimental Design}

This study was part of a larger project investigating the effects of AAS on body composition and health status in strength athletes. Here we report on the effects of AAS on body composition. To meet the number of volunteers needed for our studies we recruited a large number of strength athletes. The total number of athletes who wanted to participate in one or more studies was about 90 . Before admission to the studies, all volunteers underwent a full medical examination. Only one athlete was not admitted to the study for medical reasons.

To investigate the effect of ND on body composition, we used a randomized, double-blind, and placebo-controlled study design. All participants weekly visited the laboratory to receive the intramuscular injections. Nine subjects received a weekly intramuscular injection containing 200-mg ND (Deca-Durabolin ${ }^{\circledR}$, Organon, Oss, The Netherlands) for 8 wk. Placebo consisting of arachis oil was administered every week to the remaining seven bodybuilders who served as controls. Body composition measurements were performed at baseline (just before the first injection), after $8 \mathrm{wk}$ (i.e., $1 \mathrm{wk}$ after the last injection), and after $14 \mathrm{wk}$ (7 wk after the last injection). Power analyses $(\beta=0.80, \alpha=$ 0.02 ) for FFM by the $4 \mathrm{C}$ model revealed that, with a within-subject standard deviation of $1.3 \mathrm{~kg}$ and an expected difference of $2 \mathrm{~kg}$, the minimal number of subjects needed was five (one-tailed). The Medical Ethical Review Committee of the Maastricht University and the University Hospital Maastricht approved the study, and all subjects gave their written informed consent before participating.

\section{Subjects}

All volunteers completed an extensive questionnaire with questions related to actual health status, medical history, training habits, and the use of AAS, and underwent full physical examination to exclude any relevant disease conditions. The following exclusion criteria were used: hyper- tension, diabetes mellitus, liver disease or abnormal liver enzyme serum levels, hereditary hypercholesterolemia, elevated serum cholesterol $\left(>6.5 \mathrm{mmol} \cdot \mathrm{L}^{-1}\right)$, infertility, and smoking. Inclusion criteria were: male, bodybuilding training experience of at least $3 \mathrm{yr}$, at least four strength-training workouts per week or 8-h strength training weekly, and age between 20 and $45 \mathrm{yr}$. Only subjects (both AAS users and controls) with at least $3 \mathrm{yr}$ of strength-training experience were admitted, as the effect of weight training appears to be different between experienced and novice strength athletes. Eventually, in the present study, 16 healthy, male bodybuilders participated. Four subjects had previous experience with AAS use, whereas the remainder had never administered androgenic-anabolic substances before. The four subjects were through randomization equally distributed over the ND group and the placebo group.

\section{Monitoring Nutrition, Training, and Compliance}

Regular training and nutrition regimes were monitored by diaries filled out after 4 and $8 \mathrm{wk}$ of intervention, as well as at $6 \mathrm{wk}$ after stopping the administration of ND or placebo.

From the training data, weekly training hours were assessed. From the nutritional diaries, the intake of protein, total fat, saturated and unsaturated fat, carbohydrates, cholesterol, linolic acid, vitamins, and trace elements were calculated using the computer software program Becel (version NL04a, Unilever, The Netherlands).

Before entering the study, all subjects declared to be drug-free for at least 3 months. To objectively exclude recent AAS use and to monitor compliance during the study period in all subjects, urine samples were collected for drug analysis at baseline, after 4 and $8 \mathrm{wk}$, as well as $6 \mathrm{wk}$ after the end of the intervention period. From all urine samples collected, approximately one third was randomly selected for analysis by the Netherlands Institute for Drug and Doping Research (NIDDR), Utrecht (The Netherlands), to detect metabolites of anabolic agents.

\section{Body Composition Measurements}

Densitometry. Whole-body density was determined by underwater weighing in the fasted state. Body mass in air and underwater was determined on a digital balance, accurate to $0.01 \mathrm{~kg}$ (Sauter type E1200). Lung volume was measured simultaneously with the helium dilution technique using a spirometer (Volugraph 2000, Mijnhardt, The Netherlands).

Deuterium dilution. Subjects received an orally administered dose of $\mathrm{D}_{2} \mathrm{O}$ of $0.1 \mathrm{~g} \cdot \mathrm{L}^{-1}$ estimated TBW between 22:00 and 23:00 h (29). The appropriate amount of $\mathrm{D}_{2} \mathrm{O}(99.8 \%$, Akademie der Wissenschaften, Leipzig, Germany) was weighed out and diluted with tap water to 0.075 $\mathrm{L}$ for intake. $\mathrm{D}_{2} \mathrm{O}$ enrichment in the body fluid was measured in urine. Before $\mathrm{D}_{2} \mathrm{O}$ administration background, urine samples were taken. Urine was sampled $10 \mathrm{~h}$ after dose administration after an overnight fast from the second voiding. Isotope abundances in urine were determined in duplicate with an isotope-ratio mass spectrometer (Aqua 
Sira, VG Isogas, Cheshire, UK). Total body water was calculated as the deuterium dilution space divided by 1.04 , correcting for exchange of the deuterium label with nonaqueous hydrogen of body solids.

Bromide dilution. The extracellular water compartment was determined by bromide dilution (22). A known amount of sodium bromide $\left(60 \mathrm{mg} \mathrm{Br} \cdot \mathrm{L}^{-1}\right.$ estimated TBW; Ph.Eur.monography 190 Editie 1983 gehalte op ds $\geq$ 98.0\%, Genfarma bv, Maarssen, The Netherlands) was mixed with the $\mathrm{D}_{2} \mathrm{O}$ solution and thus administered simultaneously with the $\mathrm{D}_{2} \mathrm{O}$ dose. Venous blood samples were obtained before intake and $10 \mathrm{~h}$ after ingestion of bromide. Bromide concentration in serum ultra-filtrate was determined with HPLC. Extracellular water was estimated from the corrected bromide space (22).

Dual energy $\mathrm{x}$-ray absorptiometry. Total bone mineral content (TBMC) and total bone mineral density (TBMD) were determined by a dual-energy x-ray absorptiometer (DPX-L, Lunar Corp., Madison, WI) (23). We used the fast scan speed with a resolution of $4.8 \times 9.6 \mathrm{~mm}$ (whole body). Bone content and density were calculated by Lunar software (version 1.3z). For the whole-body scan, the subject lies in a supine position. The results were compared to the Germany Total Body White Reference Population provided by the manufacturer.

\section{Body Composition Models}

Percentage body fat was calculated by the 4C model, using body density $(\mathrm{Db})$, total body water, and bone mineral content. $\mathrm{Db}$ is calculated from body volume (BV, L), determined by underwater weighting, and body mass (BM, $\mathrm{kg})$. Water mass (TBW, $\mathrm{kg}$ ) is determined by deuterium dilution, and bone mineral mass (TBMC, $\mathrm{kg}$ ) by DXA. Total body mineral mass $(\mathrm{MM})$ is: $\mathrm{MM}=\mathrm{TBMC} / 0.824$.

The $4 \mathrm{C}$ equations are based on the same premise as the classical densitometry model, that is, body volume is the sum of volumes of compartments (20):

$\mathrm{BF} \%=(2.747 / \mathrm{Db}-0.714 \times \mathrm{TBW} / \mathrm{BM}+1.146 \times \mathrm{TBMC} / \mathrm{BM}$

$$
-2.0503) \times 100
$$

Hydration of the FFM was calculated according to (11):

Hydration fraction $=\mathrm{TBW} /(0.715 \mathrm{TBW}+3.07 \mathrm{BM}-2.765 \mathrm{BV}$

$$
-1.469 \mathrm{TBMC}
$$

Density of the FFM was calculated as follows:

$\mathrm{Dffm}=1 /(\mathrm{TBW} / \mathrm{FFM} / \mathrm{dw}+\mathrm{TBMC} / 0.824 / \mathrm{FFM} / \mathrm{dm}+$ protein/FFM/dp),

where protein $=$ FFM - TBW $-\mathrm{MM}$, and dw, dm, and dp represent the (water-, mineral-, and protein-) component densities, respectively, 0.9937, 3.038, $1.34 \mathrm{~g} \cdot \mathrm{mL}^{-1}$ according to Brozek et al. (4).

\section{Statistical Analyses}

All results are expressed as mean values, standard deviation, and ranges. Effect sizes were calculated by subtract- ing the mean values after 8 wk of ND from the mean at baseline, divided by the standard deviation at baseline. A two-tailed independent sampled $t$-test was used to establish significance of any differences between the ND-group and the placebo group. Changes in body composition before and after the use of ND were tested with a two-tailed paired $t$-test. To analyze the changes relative to the placebo group, ANCOVA tests were performed, using parameters at the start as covariable.

A one-group $t$-test was used to test whether mean FFM and mean hydration of FFM were different from their reference value. A paired, two-tailed $t$-test was used to establish whether TBMD was significantly different from agematched reference values. Level of significance was set at $P<0.05$.

\section{RESULTS}

Physical characteristics and body composition. At baseline, no significant differences between the ND and placebo group were observed with respect to the physical characteristics, FFM, FM, and \%BF (Table 1). Age range was from 19 to $44 \mathrm{yr}$ in the ND group and 20 to $42 \mathrm{yr}$ in the placebo group. Body mass and BMI varied from 54.5 to $94.6 \mathrm{~kg}$ and 21 to $27.6 \mathrm{~kg} \cdot \mathrm{m}^{-2}$ (ND) and from 69.6 to 96.6 and 23.8 to 29.8 in the placebo group, respectively. According to the $4 \mathrm{C}$ model, the body fat ranged from 7.4 to $18.8 \mathrm{~kg}$ (ND) and 12.2 to $22.0 \mathrm{~kg}$ (placebo), which amounted to 12.0-23.2 (ND) and 14.8-22.8 (placebo) percent body fat. Mean densities of the FFM (1.100 and 1.102 for ND and placebo, respectively) at baseline were not significantly different from the value of $1.1\left(\mathrm{~kg} \cdot \mathrm{L}^{-1}\right)$ used in the $2 \mathrm{C}$ model.

Training, nutrition, and compliance. Strength-training experience and weekly training hours as well as nutritional intake were comparable between both groups at baseline. During the intervention study, no significant changes in training characteristics and nutritional intake could be observed in any group. Baseline mean daily intake ( \pm SD) of energy and macronutrients were 13.4 $\pm 4.1 \mathrm{MJ}, 50.4 \pm 8.5$ En\% carbohydrates, $31.0 \pm 7.0 \mathrm{En} \%$ fat, $16.9 \pm 3.7 \mathrm{En} \%$ proteins for the ND group, and $11.9 \pm 1.6 \mathrm{MJ}, 50.4 \pm 6.8$ En\% carbohydrates, $29.5 \pm 4.1 \mathrm{En} \%$ fat, proteins $17.2 \pm$ $2.6 \mathrm{En} \%$ for the ND group.

At baseline, none of the urine samples analyzed contained any androgenic-anabolic substance or metabolites thereof. During the intervention period and after completion of the intervention, the same was true for the placebo group. In the urine samples of the ND group, only metabolites of ND were detected after 4- and 8-wk administration period. Six weeks after stopping the ND administration in some subjects, small amounts of metabolites of ND were still present.

Body composition changes. After 8-wk intervention, body mass was significantly increased by on average $2.2 \mathrm{~kg}$ in the ND group $(P<0.05)$, whereas in the placebo group no significant alteration could be observed (Table 1). Body mass increased in all ND subjects, except one. BMI was also significantly raised after the use of ND (before 25.5, after 26.7, $P<0.005$ ). FFM (by $4 \mathrm{C}$ model) and TBW 
TABLE 1. Physical characteristics, and body composition data at baseline, after 8 wk of nandrolone decanoate (ND) or placebo treatment, and at 6 wk after completion of the intervention.

\begin{tabular}{|c|c|c|c|c|c|c|c|c|c|c|c|}
\hline & \multicolumn{3}{|c|}{ Baseline } & \multicolumn{3}{|c|}{8 wk } & \multicolumn{3}{|c|}{14 wk } & \multicolumn{2}{|c|}{ ANCOVA } \\
\hline & Mean & SD & Range & Mean & SD & Range & Mean & SD & Range & $\begin{array}{c}\text { Baseline- } \\
\text { week } 8(P)\end{array}$ & $\begin{array}{c}\text { Baseline- } \\
\text { week } 14(P)\end{array}$ \\
\hline \multicolumn{12}{|l|}{ Age (yr) } \\
\hline ND & 32.7 & & $19.0-44.0$ & & & & & & & & \\
\hline Placebo & 31.0 & & $20.0-42.0$ & & & & & & & & \\
\hline \multicolumn{12}{|l|}{$\mathrm{BM}(\mathrm{kg})$} \\
\hline ND & 76.0 & 12.2 & $54.5-94.6$ & $78.2^{\star}$ & 11.9 & $57.6-96.3$ & $77.6^{\star}$ & 12.5 & $56.4-97.9$ & $<0.05$ & NS \\
\hline Placebo & 84.1 & 8.9 & $69.6-96.6$ & 84.6 & 9.1 & $69.2-97.9$ & 84.2 & 8.8 & $70.4-97.2$ & & \\
\hline \multicolumn{12}{|c|}{$\mathrm{BMI}\left(\mathrm{kg} \cdot \mathrm{m}^{-2}\right)$} \\
\hline ND & 24.7 & 2.3 & 21.0-27.6 & $25.5^{\star}$ & 2.1 & $22.2-28.1$ & $25.2^{\star}$ & 2.3 & $21.8-28.6$ & NS & NS \\
\hline Placebo & 26.8 & 2.0 & $23.8-29.8$ & 26.9 & 2.1 & $23.7-30.2$ & 26.8 & 2.2 & $24.1-30.0$ & & \\
\hline \multicolumn{12}{|l|}{ FFM (kg) } \\
\hline ND & 63.1 & 9.6 & $47.1-78.4$ & $65.7^{\star}$ & 9.7 & $50.0-80.7$ & $65.0^{\star}$ & 10.1 & $47.4-80.3$ & $<0.05$ & NS \\
\hline Placebo & 68.2 & 6.3 & $57.2-74.5$ & 69.0 & 6.6 & $57.6-74.7$ & 69.2 & 6.1 & $59.9-75.5$ & & \\
\hline \multicolumn{12}{|l|}{$\mathrm{FM}(\mathrm{kg})$} \\
\hline ND & 12.9 & 3.9 & $7.4-18.8$ & 12.5 & 3.6 & $6.7-16.9$ & 12.6 & 3.7 & $7.4-17.5$ & NS & NS \\
\hline Placebo & 15.8 & 3.4 & $12.2-22.0$ & 15.6 & 4.3 & $10.1-23.2$ & 15.0 & 4.4 & $9.1-21.7$ & & \\
\hline \multicolumn{12}{|l|}{$\% B F$} \\
\hline ND & 16.8 & 3.6 & $12.0-23.2$ & 15.8 & 3.5 & $8.9-21.1$ & 16.1 & 3.4 & $10.0-21.0$ & NS & NS \\
\hline Placebo & 18.7 & 2.5 & $14.8-22.8$ & 18.3 & 3.7 & $12.1-23.7$ & 17.6 & 3.9 & $11.2-22.3$ & & \\
\hline
\end{tabular}

BM, body mass; BMI, body mass index; FFM, fat-free mass; FM, fat mass; \%BF, percentage body fat.

* Significant difference compared with baseline values (paired $t$-test).

increased significantly in the ND group $(P<0.001$ and $P<$ 0.005 , respectively) but did not change significantly in the placebo group (Table 2). The effect sizes of BM, BMI, FFM, and TBW were $0.25,0.40,0.41$, and 0.33 , respectively. After $14 \mathrm{wk}$, these differences were still significant. All other measured variables, including FM, did not change significantly in both groups.

Analysis of the intervention effect showed that both body mass and FFM were significantly increased relative to the placebo group after $8 \mathrm{wk}$ but not after $14 \mathrm{wk}$. The 8-wk intervention with ND resulted in a significant increment of TBW in the ND group $(+1.4 \mathrm{~L})$ over the changes in the placebo group (Table 2). The increase after 14 wk was still significant relative to baseline values but not significantly different when compared with changes in the placebo group. The ECW/ICW ratios did not change significantly during the course of the study. The hydration of the FFM did not change significantly in the ND group throughout the study period nor could an intervention effect be observed.

TABLE 2. Water compartments, and total bone mineral characteristics of bodybuilders at baseline, after 8 wk of nandrolone decanoate (ND) or placebo (Plac) treatment, and at 6 wk after completion of intervention.

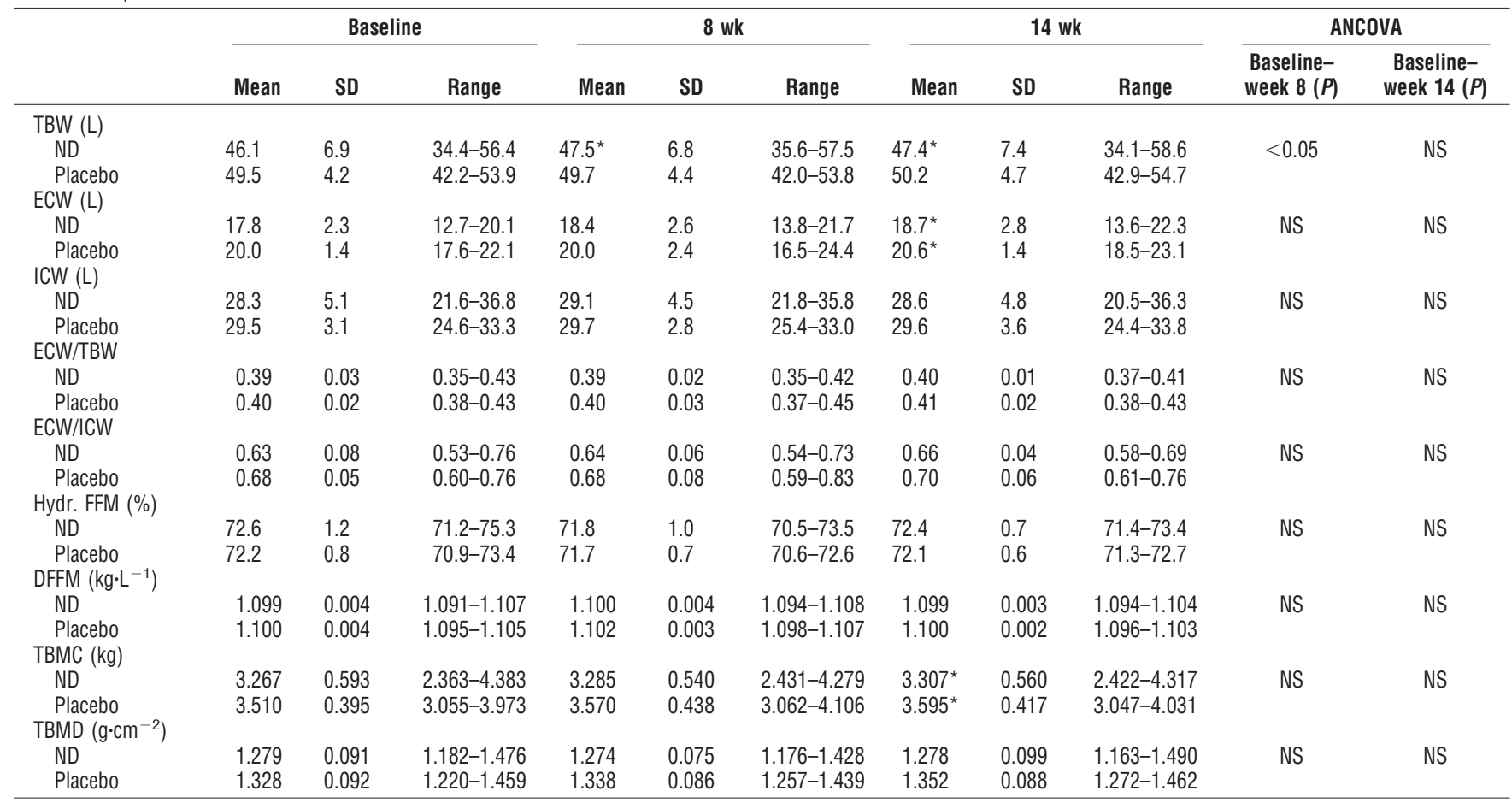

TBW, total body water; ECW, extra cellular water; ICW, intracellular water; ECW/TBW, ratio between extracellular water en total body water; ECW/ICW, ratio between extra cellular water and intracellular water; Hydr. FFM, hydration of the fat free mass; DFFM, density of the fat free mass; TBMC, total bone mineral content; TMBD, total mineral bone density.

* Significant difference compared with baseline values (paired $t$-test). 
Water compartments. ECW/ICW ratios were 0.63 and 0.68 for ND and placebo group, respectively (Table 2). The hydration of the FFM was on average $72.6 \%$ (ND baseline) and $72.2 \%$ (placebo baseline). These values and the average value of all subjects were not significantly different from the average assumed value of a normal population $73.8 \%$ (27). Compared with the placebo group, no significant effects of ND administration on hydration of the FFM could be observed.

Bone mineral density and bone mineral content. There were no significant differences of TBMC and TBMD between ND and placebo baseline values (Table 2). However, in both groups, the TBMD values were significantly higher than the reference values. During the intervention period, as well as after completion of the intervention, no significant changes of TBMD were seen in both groups. In both groups, TBMC was significantly increased compared with baseline values at the end of the study but not after 8 wk of intervention. However, the effects in the ND and placebo group were comparable (Table 2).

\section{DISCUSSION}

Main findings. The present study shows that in experienced male bodybuilders the administration of a high therapeutical dose of ND (200 $\mathrm{mg} \cdot \mathrm{wk}^{-1}$, intramuscularly) for 8 wk increased body mass and FFM, whereas FM, bone mineral content, bone mineral density, and the hydration of the FFM were unaffected. These results indicate that the observed alterations can be attributed to an increase of muscle mass.

Body mass, FM, and FFM. Body mass increased significantly after 8 wk of ND administration. The observed rise in body mass was comparable to body mass changes seen in previous studies investigating the effects of AAS on strength athletes $(2,17,19)$. Most studies investigating subjects with little or no experience with strength training show no effect of AAS on BM $(8,17)$, although recently Bhasin and coworkers (3) demonstrated that even in novice strength trainers AAS may induce increments of BM.

The results from the $4 \mathrm{C}$ model clearly show an increase of FFM after the use of ND. Because the $4 \mathrm{C}$ model belongs to the most reliable methods for determination of body composition, we can conclude that ND has a positive effect on FFM. This is in agreement with other studies using different methods for investigating the effects of AAS $(2,15,17,19)$ but is in contrast to the results from others $(5,7,8)$. In the present study, we found no significant decrease of FM after ND treatment. Although most studies did not observe an effect on FM, at least two studies reported a decrease in FM, using skinfolds and underwater weighing $(1,28)$. The difference in results may be attributed to the methods used, but the effect of differences in type and amount of drugs between studies cannot be ruled out.

Water compartments. It is still under dispute whether the AAS-induced increase in FFM consists of muscle mass or is, at least partly, due to water retention. It is reported that AAS can increase muscle mass $(3,19,26)$ and that the extent of the effect largely depends on substance(s) and dose(s) administered. On the other hand, Hervey et al. (17) showed that some changes in FFM were not only due to increase in muscle mass. They suggested that part of the increase was due to fluid retention, which is supported by the observation that AAS may increase blood volume by $15 \%$ (18). Up until now, it is not clear whether an increase of interstitial and/or ICW occurs. With the dilution techniques we used (deuterium and bromide), a distinction between interstitial fluid and blood volume is impossible, but it allows discrimination between ECW (interstitial fluid and blood volume) and ICW. Our study shows that there is no significant change in the hydration of the FFM. The hydration itself is somewhat below the assumed hydration of $73.7 \%$ (4), based on carcass analyses. Nowadays, it is well accepted that large individual variations occur within a healthy population, ranging from 70 to $76 \%$ (21). Modlesky et al. (24), however, found a significant elevated degree of hydration of weight trainers (74.8 \pm 1.2 ) compared with controls, using the same techniques as we did. The discrepancy between our data and those of Modlesky et al. can in part be explained by the different machine for the DXA measurement used and in part by lower fat percentage in the weight trainers (13.2\%) in their study.

It is to be expected that an increase in muscle mass would be accompanied by an increase in FFM, TBW, ICW, and ECW with a decreased or equal ECW/ICW ratio. Indeed, in a study on chronic obstructive pulmonary disease patients (6), it was shown that treatment with ND caused a rise in FFM and ICW compared with placebo, without expansion of ECW. Based on these results, the authors concluded that no expansion of ECW occurred and that the ND treatment resulted in an increase in metabolically active body cell mass, most likely muscle mass. Our study shows that there was indeed an increase in FFM and TBW, whereas the hydration of the FFM remained unaffected. With respect to the water compartments, the ECW/ICW ratio (ND: 0.63 , placebo: 0.68$)$ did not deviate from normal male adults (0.64 $\pm 0.06,(21))$. There was no significant change in ECW, ICW, or ECW/ICW ratio during ND use compared with placebo. The fact that the ECW/ICW ratio did not change significantly indicates that the (small) changes in ECW and ICW were in proportion to the increase in FFM and that indeed muscle mass must have increased.

Bone mineral content and bone mineral density. At baseline, the bodybuilders in the present study showed increased TBMC and TBMD compared with nonathletes. Nevertheless, there was no effect of ND on TBMC and TBMD in these subjects. Strength training has been shown to increase the bone mineral content and density, without any additional effect of short-term self-administration of AAS (9). On the other hand, long-term treatment with AAS has been shown to exert a (small) positive effect on bone mineral density of several bones in several populations, for example, osteoporosis in males (13) and in postmenopausal women (25). Due to the short-term intervention period in our study, a detectable effect on TBMC and TBMD in the present study was not expected, although we performed 
measurements with more accurate and sensitive equipment than used by Fiore and coworkers (9).

\section{CONCLUSIONS}

Using the 4C model for determination of body composition, the present study proves that the effect of ND administration $\left(200 \mathrm{mg} \cdot \mathrm{wk}^{-1}\right.$, intramuscularly, for $8 \mathrm{wk}$ ) additionally to regular strength training increases body mass and FFM in experienced, male bodybuilders, whereas FM re-

\section{REFERENCES}

1. AlÉn, M., and K. HaKkinen. Androgenic steroid effects on serum hormones and on maximal force development in strength athletes. Int. J. Sports Med. 27:38-46, 1987.

2. Alén, M., K. Hakkinen, and P. V. Komi. Changes in neuromuscular performance and muscle fiber characteristics of elite power athletes self-administering androgenic and anabolic steroids. Acta Physiol. Scand. 122:535-544, 1984.

3. Bhasin, S., T. W. Storer, N. Berman, et al. The effects of supraphysiologic doses of testosterone on muscle size and strength in normal men. N. Engl. J. Med. 335:1-7, 1996.

4. Brozek, J., F. Grande, J. T. Anderson, and A. Keys. Densitometric analysis of body composition: revision of some quantitative assumptions. Ann. N. Y. Acad. Sci. 110:113-140, 1963.

5. Casner, S. J., R. G. Early, and B. R. Carlson. Anabolic steroid effects on body composition in normal young men. J. Sports Med. Phys. Fitness 11:98-103, 1971.

6. Creutzberg, E. C. Anabolic management in patients with COPD. Maastricht University, Department of Pulmonology, Maastricht, 2000, pp. 178

7. Crist, D. M., P. J. Stackpole, and G. T. Peake. Effects of androgenic-anabolic steroids on neuromuscular power and body composition. J. Appl. Physiol. 54:366-370, 1983.

8. FAHEY, T. D., and C. H. Brown. The effects of an anabolic steroid on the strength, body composition, and endurance of college males when accompanied by a weight training program. Med. Sci. Sports 5:272-276, 1973.

9. Fiore, C. E., E. Cottini, C. Fargetta, S. G. Di, R. Foti, and M. RASPAGLIESI. The effects of muscle-building exercise on forearm bone mineral content and osteoblast activity in drug-free and anabolic steroids self-administering young men. Bone Miner. 13: 77-83, 1991.

10. Fogelholm, M. and W. D. v. Marken Lichtenbelt. Review. Comparison of body composition methods: a literature analysis. Eur. J. Clin. Nutr. 51:495-503, 1997.

11. Fuller, N. J., S. A. Jebb, M. A. Laskey, W. A. Coward, and M. Elia. Four-component model for the assessment of body composition in humans: comparison with alternative methods, and evaluation of the density and hydration of fat-free mass. Clin. Sci. 82:687-693, 1992.

12. Fuller, N. J., M. A. Laskey, and M. Elia. Assessment of the composition of major body regions by dual-energy X-ray absorptiometry (DEXA), with special reference to limb muscle mass. Clin. Physiol. 12:253-266, 1992.

13. Hamdy, R. C., S. W. Moore, K. E. Whalen, and C. Landy. Nandrolone decanoate for men with osteoporosis. Am. J. Ther. 5:89-95, 1998.

14. Hartgens, F. Androgenic-anabolic steroids use in strength athletes; effects on body composition and cardiovascular system. $\mathrm{Ph} . \mathrm{D}$. dissertation. Maastricht University, Dept. Movement Sciences, Maastricht, 2001, pp. 158.

15. Hartgens, F., W. D. v. Marken Lichtenbelt, S. Ebbing, N. B. J. VollaArd, G. Rietjens, and H. Kuipers. Androgenic-anabolic mained unaffected. Because ND administration increased total body water, but did not exert any significant effect on $\mathrm{ECW} / \mathrm{ICW}$ ratio nor on bone mineral metabolism, these data indicate that the changes of body mass and FFM can be attributed to an increase of muscle mass.

We thank Loek Wouters from the Department of Human Biology (Maastricht University) for accurately performing the deuterium analyses, Lia van lersel from the Department of Nuclear Medicine of the University Hospital Maastricht for carrying out the DXA measurements, and Gerard Hornstra for critically reading the manuscript.

steroids induced changes of anthropometry and body composition in strength athletes. Physician Sportsmed. 29:49-66, 2001.

16. Hartgens, F., W. D. v. Marken Lichtenbelt, S. Ebbing, N. B. J. VollaArd, G. Rietjens, and H. Kuipers. Body composition and anthropometry in body builders: regional changes due to nandrolone decanoate administration. Int. J. Sports Med. 22:235-241, 2001.

17. Hervey, G. R., A. V. Knibbs, L. Burkinshaw, et al. Effects of methandienone on the performance and body composition of men undergoing athletic training. Clin. Sci. 60:457-461, 1981.

18. Holma, P. Effect of an anabolic steroid (methandienone) on central and peripheral blood flow in well-trained male athletes. Ann. Clin. Res. 9:215-221, 1977.

19. Kuipers, H., J. A. G. Wijnen, F. Hartgens, and S. M. M. Willems. Influence of anabolic steroids on body composition, blood pressure, lipid profile and liver functions in body builders. Int. J. Sports Med. 12:413-418, 1991.

20. Lohman, T. G. Advances in Body Composition Assessment, 1 st Ed. Champaign, IL: Human Kinetics, 1992, 150 pp.

21. Marken Lichtenbelt, W. D., and M. Fogelholm. Increased extracellular water compartment, relative to intracellular water compartment, after weight reduction. J. Appl. Physiol. 87:294-298, 1999.

22. Marken Lichtenbelt, W. D. v., A. Kester, E. M. BaArends, and K. R. Westerterp. Bromide dilution in adults: optimal equilibration time after oral administration. J. Appl. Physiol. 81:653-656, 1996.

23. Mazess, R. B., H. S. Barden, J. P. Bisek, and J. Hanson. Dualenergy $\mathrm{x}$-ray absorptiometry for total-body and regional bonemineral and soft-tissue composition. Am. J. Clin. Nutr. 51:1106$1112,1990$.

24. Modlesky, C. M., K. J. Cureton, R. D. Lewis, B. M. Prior, M. A. Sloniger, and D. A. Rowe. Density of the fat-free mass and estimates of body composition in male weight trainers. J. Appl. Physiol. 80:2085-2096, 1996.

25. Passeri, M., M. Pedrazzoni, G. Pioli, L. Butturini, A. H. Ruys, and M. G. CortenRAad. Effects of nandrolone decanoate on bone mass in established osteoporosis. Maturitas 17:211-219, 1993.

26. Sinha-Hikim, I., J. ArtaZA, L. Woodhouse, et al. Testosteroneinduced increase in muscle size in healthy young men is associated with muscle fiber hypertrophy. Am. J. Physiol. 283:E154-E164, 2002.

27. SIRI, W. E. Body composition from fluid spaces and density: analysis of methods. In: Techniques for Measuring Body Composition, J. Bozek and A. Henschel (Eds.). Washington, DC: National Academy of Sciences, 1961, pp. 223-224.

28. WARD, P. The effect of anabolic steroid on strength and lean body mass. Med. Sci. Sports 5:277-282, 1973.

29. Westerterp, K. R., W. D. v. Marken Lichtenbelt, and L. WoutERS. The Maastricht protocol for the measurement of body composition and energy expenditure with labeled water. Obes. Res. 3:49-57, 1995. 